\title{
Implementation of a Higher Quality dc Power Converter
}

\author{
Nader N. Barsoum
}

Curtin University of Technology, Miri, Malaysia.

Email: nader.b@curtin.edu.my

Received September $3^{\text {rd }}, 2009$; revised October $8^{\text {th }}, 2009$; accepted October $15^{\text {th }}, 2009$.

\begin{abstract}
Many single and three-phase converters are well developed, and covered up in most of electric markets. It is used in many applications in power systems and machine drives. However, an exact definite output signal from the dc side still not recognized. The waveforms of output voltage and current demonstrate an imperfect dc signal and constitute losses, harmonic distortion, low power factor, and observed some ripples. An approximately perfect rectifier bridge is the aim of this research. Perhaps it gives the ability to identify the parameters of the converter to obtain, as much as possible, a perfect dc signal with less ripple, high power factor and high efficiency. Design is implemented by simulation on Power Simulator PSIM, and practically, a series regulator LM723 is applied to provide regulating output voltage. Comparisons of both simulation and hardware results are made to observe differences and similarities.
\end{abstract}

Keywords: Simulation, Microcontroller, Converter, Feedback, Power Factor, Design

\section{Introduction}

In industrial application, Direct Current (dc) is used for controlling application such as Programmable Logic Controller (PLC), Microcontroller, dc motor and many commercial and domestic appliances [1-4]. Rectifier has become a popular power source [5-7] for these appliances because of its reduced cost and relatively low sensitivity to supply voltage variations under normal operating conditions. Stability is the key issue in these applications as it involves certain precision and decision making [8]. These systems are usually employed in automotive and aerospace applications $[6,9]$ where tiny little error in the supply (unstable dc) might cause a large disaster.

The processed output voltage, current as well as frequency, will be as desired by the load. If the power processor's output can be regarded as a voltage source, the output current and the phase angle relationship between the output voltage and the current depend on the load characteristic. Also, normally, a feedback controller will be provided to perform comparison to the output of the power processor unit with a desired reference value, and the controller minimizes the error between the two.

Generally, design of converter that can be considered as a good design, should cover few essential aspects [10]. One of them will have to be efficient, which can be considered as the ultimate goal of design in power electronic. Besides that, a few current issues can be directly and in- directly affected the course of a design of a converter. One of these significant issue is the line quality, whereby is critical to ensure that the utility lines and transformer would supply undistorted wave voltage to customers. The source and line inductances play an important role in the line quality issue. With the presence of the reactive power to the line, it increases the volt-ampere rating. Thus, the input ac line voltage becomes distorted from the higher peak currents. As a result, high reactive components are being used. This is a drawback because a poor power factor causes heavy expenses to the user.

Besides that, the growing concern regarding harmonic pollution of the power distribution system creates awareness for clean ac line current and a power factor close to unity. The phase angle of the fundamental harmonic current $[2,5]$ with respect to the line voltage is a very important parameter that determines the power factor. These issues are some of the critical aspects that should be taken into consideration when designing a good converter.

Power factor correction is achieved by the addition of capacitor in parallel with the connected motor circuits and can be applied at the starter, or applied at the switchboard or distribution panel. The resulting capacitive (leading) current is used to cancel the inductive (lagging) current flowing from the supply.

The microcontroller program performs this. The microcontroller is programmed in such a way that it will perform the checking the phase difference every $1 / 2 \mathrm{MHz}$ 
second (microcontroller running on $2 \mathrm{MHz}$ crystal) and calculate out the phase different between the current and voltage waves. The calculated value will be converted into signal to activate appropriate capacitor to correct the power factor $[2,11,12]$.

Capacitors are installed parallel to the source, waiting for the signal from the microcontroller. When microcontroller sends signal, the signal will be amplified via MOSFET and activate a relay. The relay hence will turn on the capacitor. The feedback circuit is designed in such a way that the system is allowed to be a capacitive system but not an inductive system.

\section{Implementation of Single Phase Converter}

\subsection{Step-Up Converter with Feedback Control}

To further improve the output signal generated, by means of current shaping, it can be archived through step-up converter with feedback control applied at dc side of the rectifier to replace the $\mathrm{LC}$ filtering component. With this arrangement, it is possible to shape the input current drawn by the rectifier bridge to be sinusoidal and in phase with the input voltage. For the purpose of better illustration, Figure 1 shows the circuit configuration. At the input side, the input current $i_{s}$ is desired to be sinusoidal and in phase with input voltage $V_{s}$, also, at the full bridge rectifier output, $i_{L}$ and absolute value of $V_{s}$ will have the same waveform as well. For the theoretical analysis below, the power loss of the rectifier bridge and the step-up converter will be neglected due to the fact that the losses are somewhat small.

Thus, we have, for $\hat{V}_{S}=\sqrt{2} V_{S}$ and $\hat{I}_{S}=\sqrt{2} I_{S}$, the input power can be expressed as:

$$
P_{i n}(t)=\hat{V}_{S}|\sin \omega t| \hat{I}_{S}|\sin \omega t|=V_{S} I_{S}-V_{S} I_{S} \cos 2 \omega t
$$

The average value of current $I_{d}$ can be expressed as:

$$
I_{d}=I_{\text {load }}=\frac{V_{S} I_{S}}{V_{d}}
$$

Also, the current through the capacitor is:

$$
i_{C}(t)=-\frac{V_{S} I_{S}}{V_{d}} \cos 2 \omega t=-I_{d} \cos 2 \omega t
$$

From these expressions, the ripple in $V_{d}$ can be determined by means of estimation, as shown in Equation (4):

$$
V_{d, \text { ripple }}(t) \approx \frac{1}{C_{d}} \int i_{C} d t=\frac{I_{d}}{2 \omega C_{d}} \sin 2 \omega t
$$

The step-up converter shown in Figure 1 is operating in current-regulated mode, as our main purpose is to shape the input current of the step-up converter. The feedback control, represented in block diagram, is shown in Figure 2. This feedback control serves as the purpose of comparing the output generated with a reference value, in order to minimize the error between these two.

$i_{L} *$ shown in Figure 2 is the reference value of the current $i_{L}$ in the step-up converter. The amplitude of $i_{L}{ }^{*}$ should be such that as to maintain the output voltage at a reference level of $V_{d}{ }^{*}$, in spite of the variation of load and the fluctuation of the line voltage from its nominal value. The waveform of $i_{L} *$ is obtained by means of measuring absolute value of $V_{s}$ by a resistive potential divider and multiplying it with the amplified error between the reference value $V_{d} *$ and the actual measured value of $V_{d}$. On the other hand, the actual current $i_{L}$ is sensed, usually by measuring the voltage across a small resistor inserted in the return path $\mathrm{pf} i_{L}$. The status of the switch in the step-up converter is controlled by comparing the actual current $i_{L}$ and $i_{L} *$.

If constant frequency is applied for this feedback control, the ripple current can thus be expressed as:

$$
I_{\text {rip }}=-\frac{\left(V_{d}-\left|V_{S}\right|\right)\left|V_{S}\right|}{f_{S} L_{d} V_{d}}
$$

In terms of maximum ripple current, it can be expressed as:

$$
I_{\text {rip }, \max }=\frac{V_{d}}{4 f_{S} L_{d}}
$$

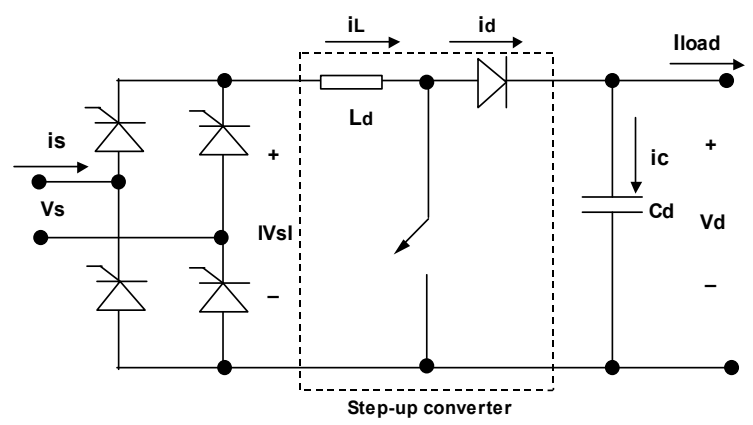

Figure 1. Step-up converter for current shaping

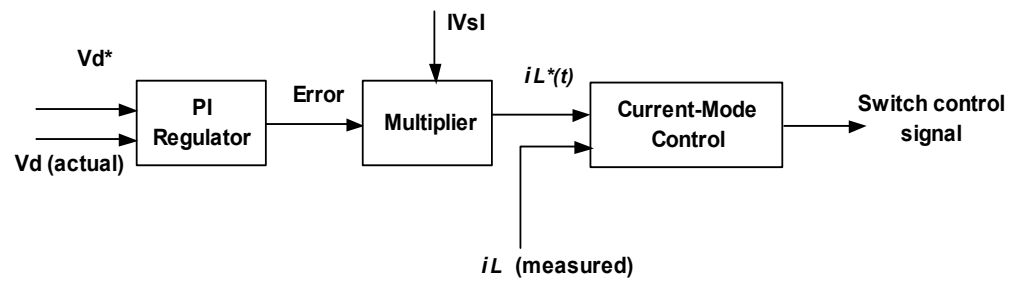

Figure 2. Feedback control block diagram 
The step-up converter topology is well suited for the input current shaping method because when the switch is off, the input current directly feeds the output stage.

\subsection{Complete Design with Step-Up Converter at dc Side}

The feedback controller shown above operates by comparing the output generated with a reference value set. In simulation, the actual output current is sensed by a current sensor connected at dc side of the rectifier, and this actual value of $I_{d}$ is sent to negative probe of the summer. The reference value of $I_{d}$ is transmitted through positive probe of summer. The comparison of signal will take place at the comparator, with signal generated from PI controller and triangular wave.

For better reference, Figure 3 shows the complete design of single-phase controlled rectifier with step-up converter and feedback control implemented in PSIM.

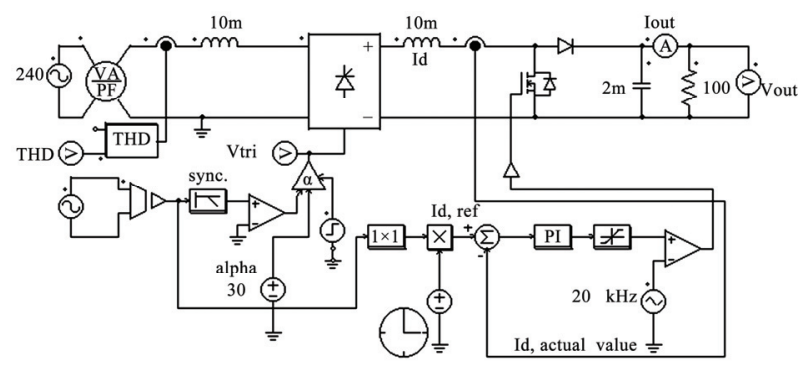

Figure 3. Thyristor converter with step-up converter
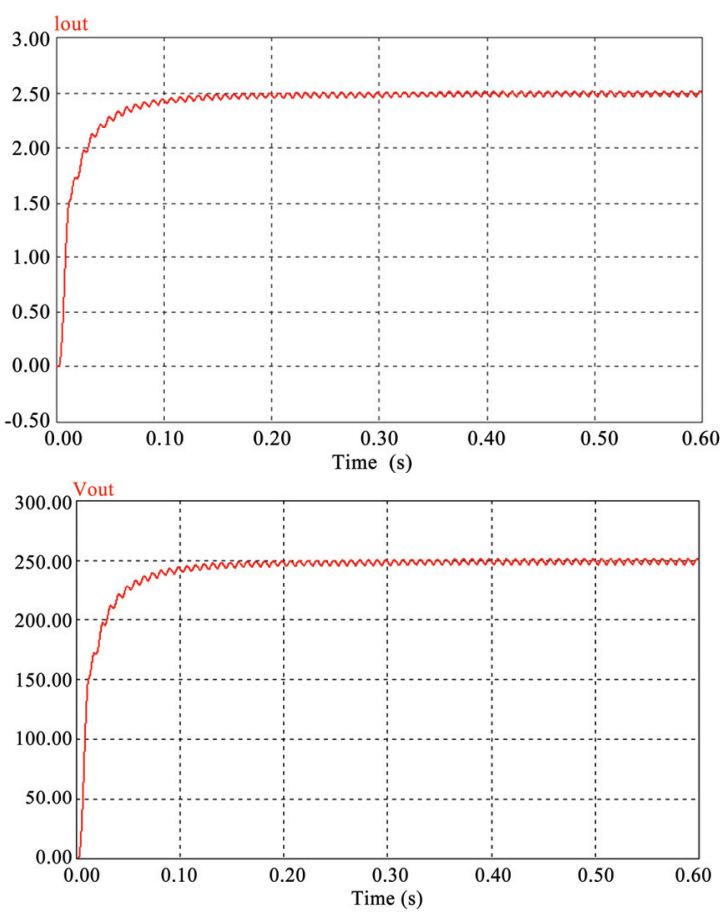

Figure 4. Waveforms for output voltage and output current

\subsection{Simulation Results}

Simulation is carried out based on similar parameters applied on rectifier design without step-up converter in order to observe the difference between these two designs. Similarly, for better illustration, simulation results corresponding to firing angle of $30^{\circ}$ are shown in Figure 4.

\subsection{Comparison of Results}

Comparison between the two types of rectifier design configuration is given in Table 1 . It shows some of the essential parameters corresponding to firing angle of $0^{\circ}$.

The table indicates that thyristor converter with step-up converter and feedback control shows an improvement in overall aspects. In terms of THD, it improved from 49\% to $21 \%$. While as for power factor produced, it increased from 0.81 to 0.98 .

\subsection{Design of Hardware}

In hardware manner, the variable dc output will be controlled by means of applying a regulator chip LM723 to control the output voltage generated. This design method is rather different than the design approach implement in simulation. One of the reasons for this is that an exact solution for hardware implementation based on design in simulation has not yet been found; these reasons will be outlined in more details in problems encountered and suggestions for further development. For this practical design, in terms of rectifying component, Diode Bridge will be applied for this hardware implementation. For better illustration, the circuit diagram for the practical design is shown in Figure 5.

For this particular design, the input voltage $V_{s}$ is equal to $18 \mathrm{~V}$, which is stepped down by a transformer, not shown in the figure. Diode D1, D2, D3 and D4 forms the diode bridge, KP206G. Also, another diode, IN539 is applied at dc side. One of the functions for this diode is to act as a feedback blocker, whereby it steers any current that might be coming from the device under power around the regulator to prevent the regulator from damages. These sorts of reverse current usually occur when the rectifier is been powered down.

\subsection{Operation Analysis}

Basically, this practical rectifier design applies a different

Table 1. Comparison of results

\begin{tabular}{l|c|c}
\hline \multicolumn{1}{c}{ Parameters } & \multicolumn{2}{c}{ Types of rectifier configuration } \\
& $\begin{array}{c}\text { Without Step-up } \\
\text { Converter }\end{array}$ & $\begin{array}{c}\text { With Step-up converter } \\
\text { and feedback control }\end{array}$ \\
\hline Output voltage & $200 \mathrm{~V}$ & $246.5 \mathrm{~V}$ \\
Ripple voltage & $4.3 \mathrm{~V}(2.15 \%)$ & $3 \mathrm{~V}(1.21 \%)$ \\
THD & $49 \%$ & $21 \%$ \\
Power Factor & 0.81 & 0.98 \\
\hline
\end{tabular}




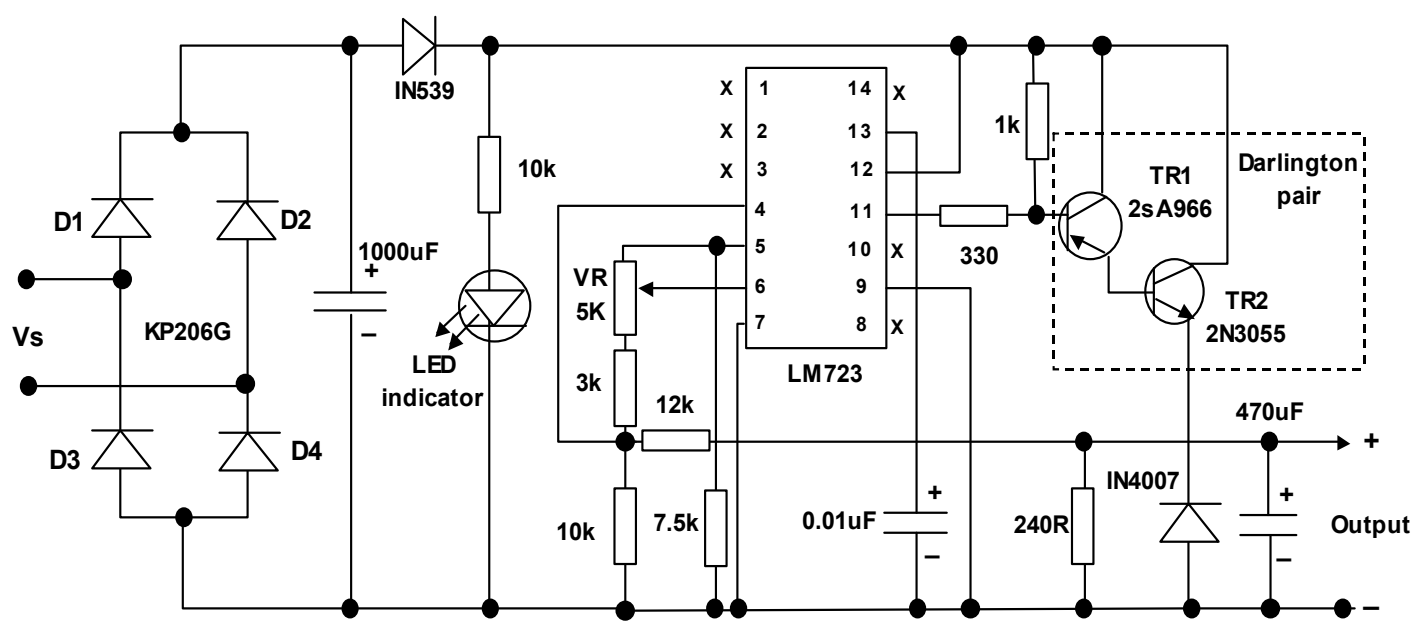

Figure 5. Circuit diagram of practical converter design

comparable approach to implement in simulation. Referring to Figure 5, with the use of the transformer, to steps down the input voltage to $18 \mathrm{~V}$. The voltage rectified by the diode bridge to produce unfiltered dc output voltage. This unfiltered dc output voltage will contain big ripple and is pulsating. This pulsating output voltage will then been filtered by the capacitive filter of $1100 \mu \mathrm{F}$ capacitor in order to manageable for the regulator.

As noticed in Figure 5, there's only capacitive filtering applied to the design, this is due to the fact that in lowpower applications, the inductor required for rectification design could be a costly item, that's the main reason most low-power converters dispense with the inductor and apply a direct capacitive filtering method. With no load, the dc voltage across the terminals of the filter is going to be 18 to 30 volts.

The regulation is obtained using the Darlington pair (TR1 and TR2). They in turn are controlled by the 723 regulator. 723 has its own internal highly regulated voltage reference supply (pin 6). Internally the 723 compare this reference voltage to the output of the power supply and it is varied by means of variable resistor VR, shown in Figure 5. This sets the output voltage. The regulation process evolves around pin 11 and pin 6 of LM723 regulator. Pin 11 of 723-regulator control voltage supply, and this $\mathrm{V}_{\mathrm{C}}$ will trigger the base of TR1, which is 2SA966, PNP transistor, which will act as a simple amplifier to increase the current available to drive the base of the pass transistor, i.e. TR2 2N3055. This explains the function of Darlington transistor pair applied.

Capacitance of $0.01 \mu \mathrm{F}$ connected to frequency component (pin 13) of 723-regulator function as a transient response improver, which improves the response of the regulator when it is operating during high frequencies. Regulated dc output, will be filtered again by capacitance of $470 \mu \mathrm{F}$ to produce an output voltage that contains a minimum ripple and close to pure dc voltage. Necessary protective device have all been installed in this practical design such as fuses, metering component for voltage and current, not shown in the figure. Note here, these metering component are meant for as a guideline as the accuracy of these meters might be $a \pm 1 \mathrm{~V}$ difference for the case of voltmeter. Therefore, for better accuracy, a multimeter should be used.

Figure 6 shows an overall view of practical design. Note, TR2 and 2N3055 are mounted on a huge heat sink. This step is necessary, as the heat sink installed will helps to dissipate the massive flow of heat generated to the pass transistor.

\subsection{Comparison of Results}

As design implemented from hardware manner, which applied the diode bridge as main conversion component, for comparison purpose, we compare the results from design in the simulation corresponding to firing angle of $0^{\circ}$. Table 2 shows results from both of the design. It shows that the design implemented in simulation use $20 \mathrm{~V}$ as

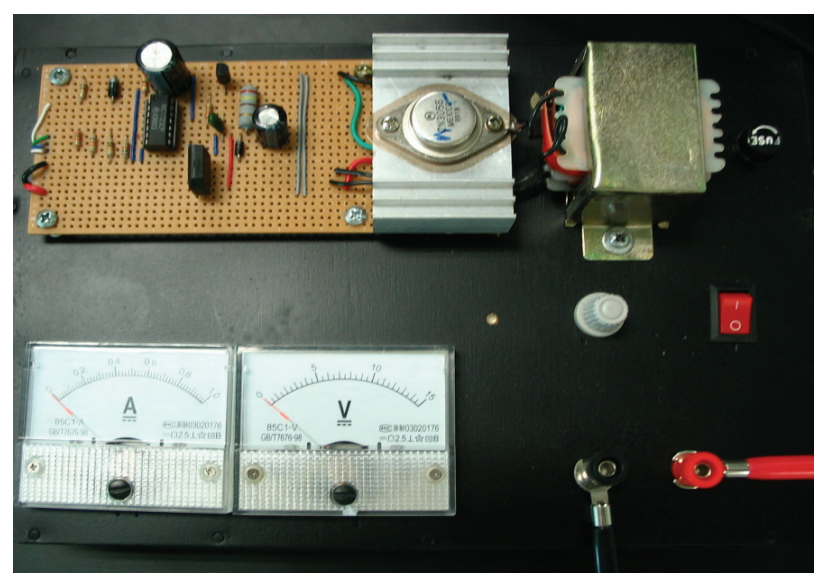

Figure 6. Overall view of practical design implemented 
Table 2. Comparison of results

\begin{tabular}{lcc}
\hline Parameters & \multicolumn{2}{c}{ Design method } \\
& $\begin{array}{c}\text { Design from simulation } \\
\text { (firing angle }=\mathbf{0}^{\circ} \text { ) }\end{array}$ & Practical Design \\
\hline Input Voltage & $20 \mathrm{~V}$ & $18 \mathrm{~V}$ \\
Output Voltage & $37.7 \mathrm{~V}$ & $15.8 \mathrm{~V}$ \\
Ripple voltage & $1.24 \mathrm{~V}(3.3 \%)$ & $800 \mathrm{mV}(5.06 \%)$ \\
Output Current & $0.37 \mathrm{~A}$ & $0.18 \mathrm{~A}$ \\
Output power & $13.9 \mathrm{~W}$ & $2.84 \mathrm{~W}$ \\
THD & $30.2 \%$ & $47.7 \%$ \\
Power Factor & 0.96 & 0.90 \\
\hline
\end{tabular}

input voltage, as main concern is on low power application. While in hardware design, the input voltage is in $18 \mathrm{~V}$, which is stepped down by a step down transformer. $18 \mathrm{~V}$ secondary side voltage is one of the common rates of voltage used in terms of low voltage application.

Results shown clearly indicate that the simulation have gain advantages over the practical design. These are shown through power factor produced and total harmonic distortion created. However, the difference in terms of power factor and ripple voltage didn't show a big difference. The only major difference comes from the total harmonic distortion.

Note that when comes to comparison of results from simulation and practical manner, some slight discrepancies should be taken into account. This is due to the fact that from simulation point of view, generally ideal components are used and so they have theoretical constraints associated with them, which is possible to differ slightly from the actual physical component. As for practical converter, there might be losses in the process of stepping down voltage as well as where conversion from ac to dc takes place. Besides that, each of the components, particularly resistors and diode used, all contribute to losses generated.

\section{Implementation of Three Phase Converter}

\subsection{Feedback Control Loop}

As far as power factor and total harmonic distortion is concern, inductors are added at the source to compensate the capacitive value produced by the capacitor at the filtering device. This solution is being taken one step further to install a feedback control device to compensate the inductive value produced by the load in case the converter is used for a dc motor. Thus, a feedback control loop is proposed to improve the power factor of the system. This is shown in Figure 7.

Power factor correction is achieved by adding capacitors in parallel with the connected motor circuit and can be applied at the starter or the switchboard or distribution panel. The resulting capacitive current is leading current and it is used to compensate the lagging inductive current flowing from the supply.

This correction task is carried out by micro-controller, which is specially designed to perform the checking and correcting the incoming voltage and current. External comparator MCP6024 is used to convert the analogue signal to 2-bit digital signal. The converted signal is then input into the microcontroller to perform phase difference analysis.

Signals that are about to be input into the microcontroller are phase-shifted voltage and the voltage that represents the current. Phase-shifted voltage is obtained near the load for the voltage at the load will represent the voltage's phase shift. Voltage's phase is taken as variable while the current's phase is taken as constant. If the load is capacitive, the voltage's phase is lagging the current's phase. If the load is inductive, the voltage phase is leading the current phase.

The microcontroller will observe the voltage phase. When the microcontroller detected a ' 1 ' for voltage, it will then observe the current phase (represented by voltage across the load). If the current is not detected, it will return a ' 1 ' and activate capacitor $\mathrm{A}$ from the capacitor bank. After that, it will check both the voltage and current phases again. If the current phase is again not detected when the voltage phase is detected, it will return another ' 1 ' and now, activate capacitor B. The whole process will repeat until the capacit or $\mathrm{E}$ in the capacitor bank is activated, or, the current is detected when the voltage phase is detected. The process algorithm is shown

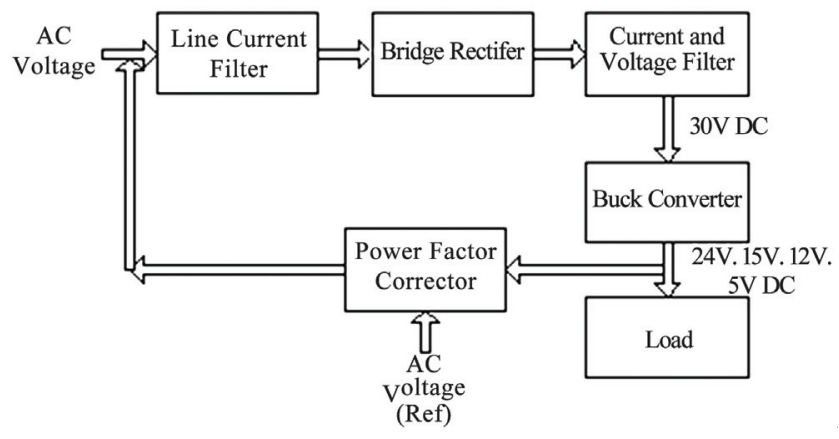

Figure 7. Feedback controlled three phase converter 
in Figure 8. Every time when there is a change in the load (manually), then the power factor corrector has to be reset in order to function properly. The power factor correction algorithm is being implemented in MATLAB simulation. The program enables the user to input the load inductance and the program will return the number of capacitor of the dedicated value needed. It can also display the uncompensated and the compensated waveforms. The output is shown in Figure 9.

In Figure 9, the load used is $10 \mathrm{k} \Omega$ and the load inductor is $1 \mathrm{mH}$. There are 99 capacitors rated $100 \mathrm{pF}$ needed to compensate the inductance. It is understood that the compensation could not be $100 \%$ because the signal is being sampled with Nyquist sampling rate. The program is written in such a way that the microcontroller will ensure that the system is capacitive rather then inductive.

\subsection{Integration of Designs}

The designs are being integrated together to form a complete ac-dc converter with high power factor, low harmonic distortion and low voltage ripple. This is shown in Figure 10 following Figure 7.

It is noticed that the $1 \mathrm{M} \Omega$ resistor at the output of the rectifier circuit is being removed. This is to allow the current to flow completely into the load circuit without any additional current drawn over unnecessary load.

The duty cycle D of the Buck converter is set to four mode of operation, namely, $0.167,0.4,0.5$ and 0.8 . These duty cycles will give $5 \mathrm{~V}, 12 \mathrm{~V}, 15 \mathrm{~V}$ and $24 \mathrm{~V}$ respectively.

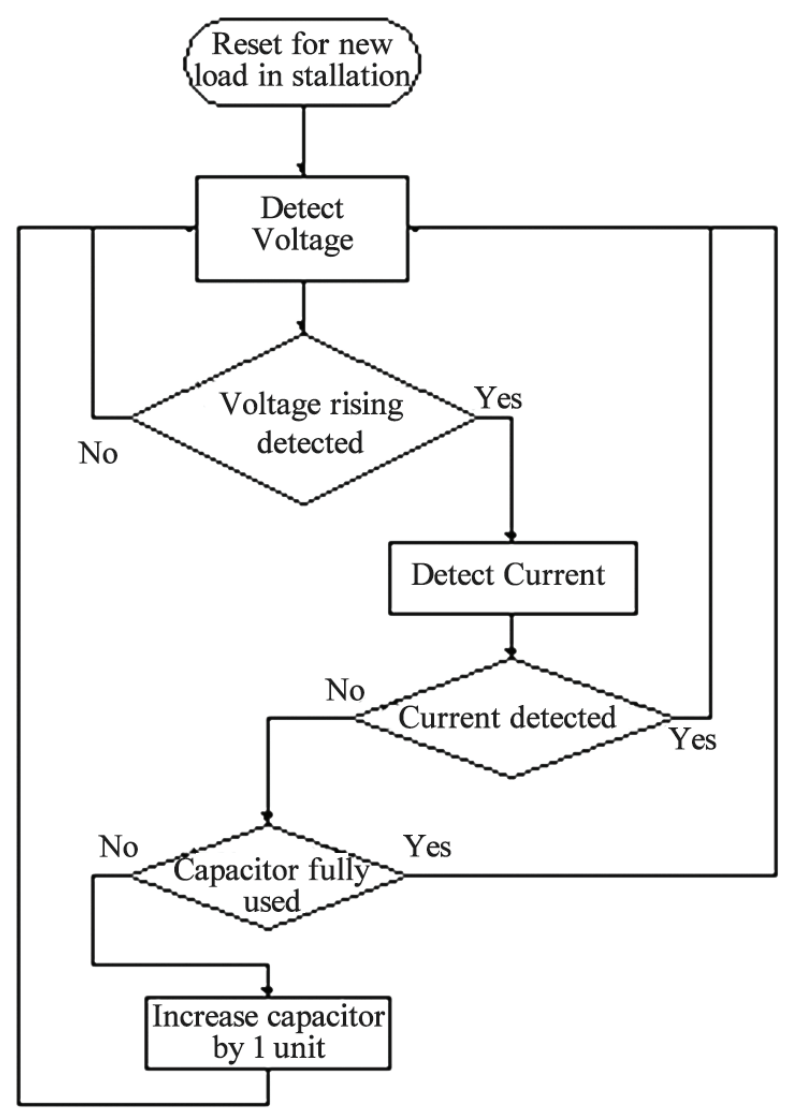

Figure 8. Power factor corrector flowchart
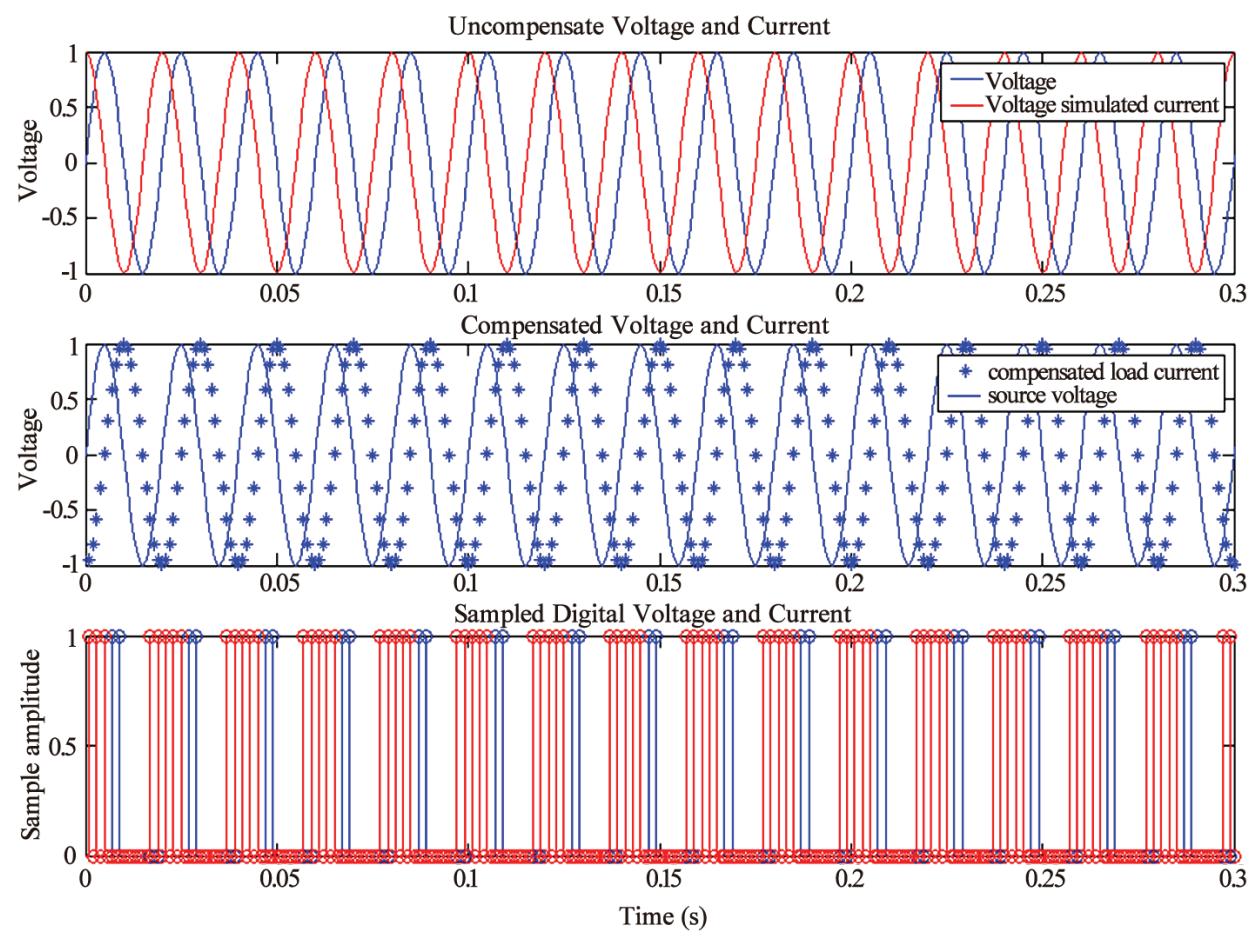

Figure 9. Power factor correction made onto the inductive system 
It is also noticed that the source rms line voltage is being step up to $23 \mathrm{~V}$. This is because, the diodes used are no longer ideal diode, and a $0.7 \mathrm{~V}$ voltage drop is introduced across the diode. Increasing the source voltage to $23 \mathrm{~V}$ rms will ensure that the four duty cycle operation modes will achieve the desired output.

\subsection{Simulation}

At $\mathrm{D}=0.8$, the desired output is $24 \mathrm{~V}$ and $10 \mathrm{k} \Omega$ sample load is placed at the output of the ac-dc converter. The output current and voltage is shown in Figure 11:

The output is being evaluated in frequency domain as is shown in Figure 12.

It is noticed that the output current and voltage shows an extremely low ripple and the rise time is less than 0.4 seconds. In frequency domain, the frequency component is less than $200 \mathrm{~Hz}$, which means, the harmonic of the output is extremely low, even the fundamental frequency $(300 \mathrm{~Hz})$ is almost completely reduced.

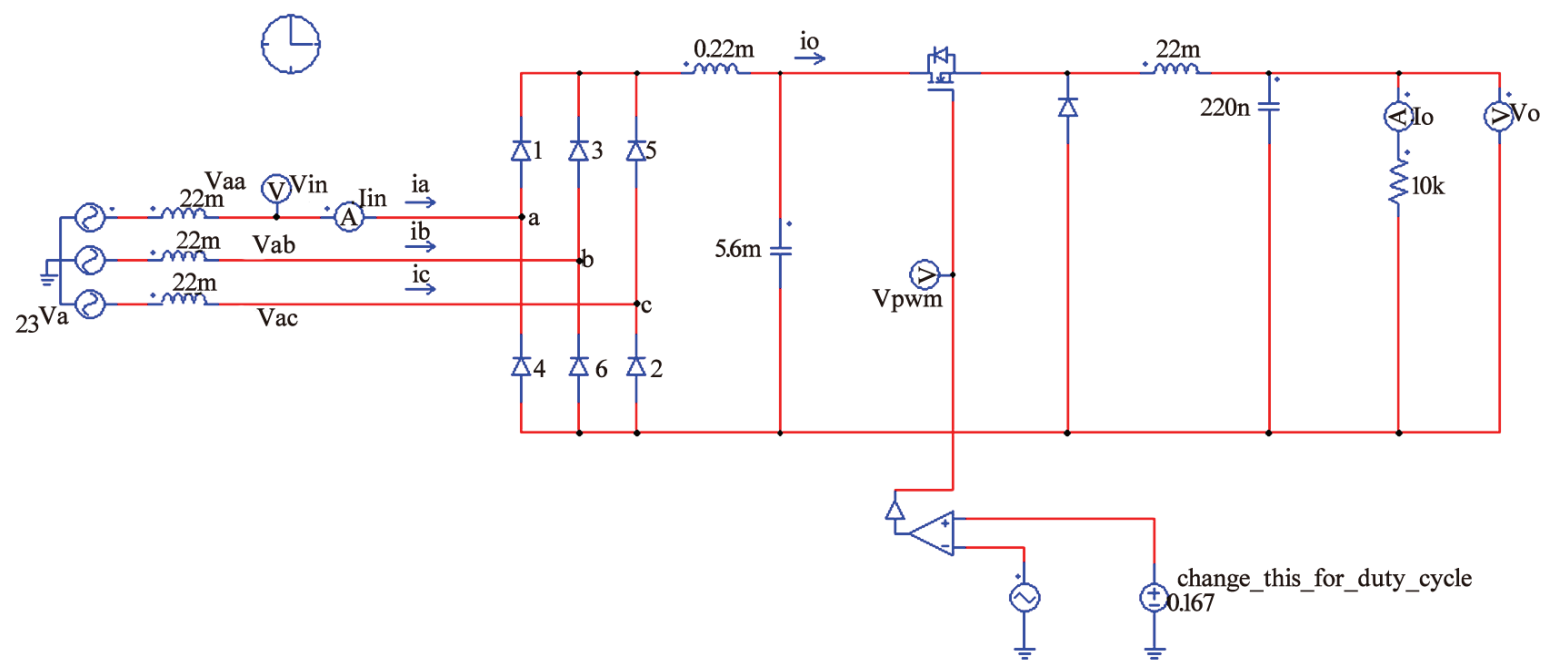

Figure 10. Integration of the rectifier and Buck converter
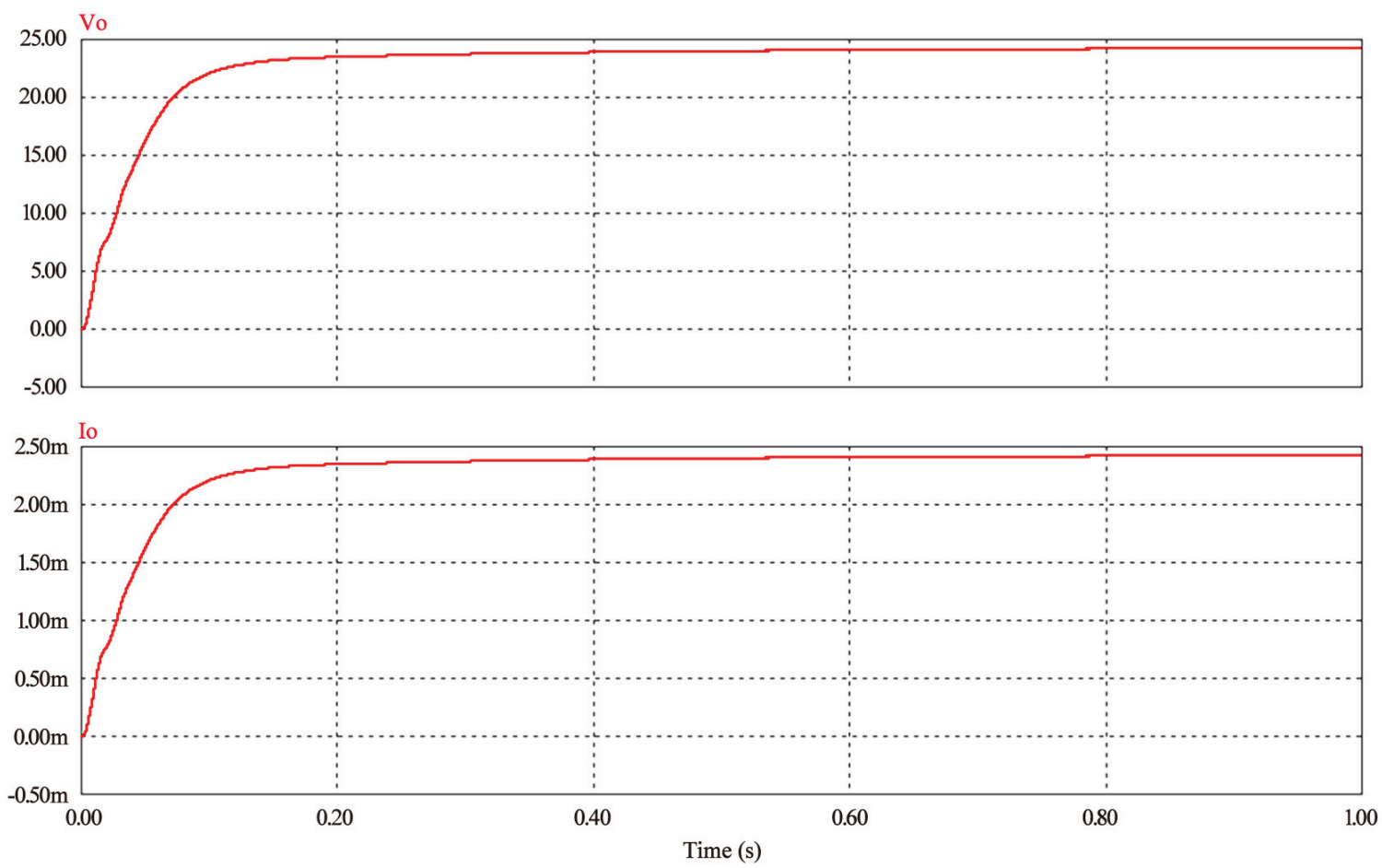

Figure 11. Output current and voltage waveform with $D=0.8$ 

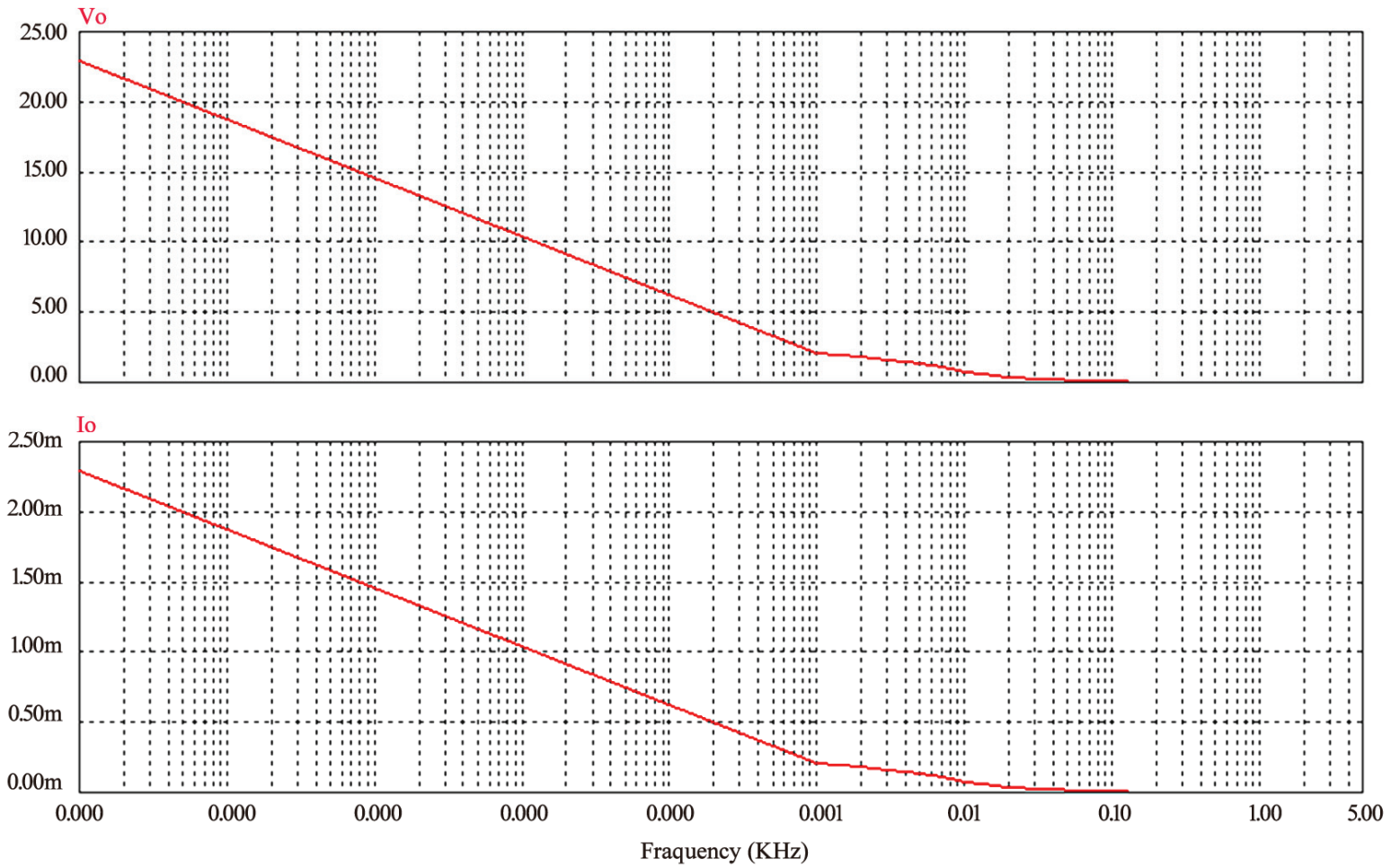

Figure 12. Output current and voltage in frequency domain with $D=0.8$

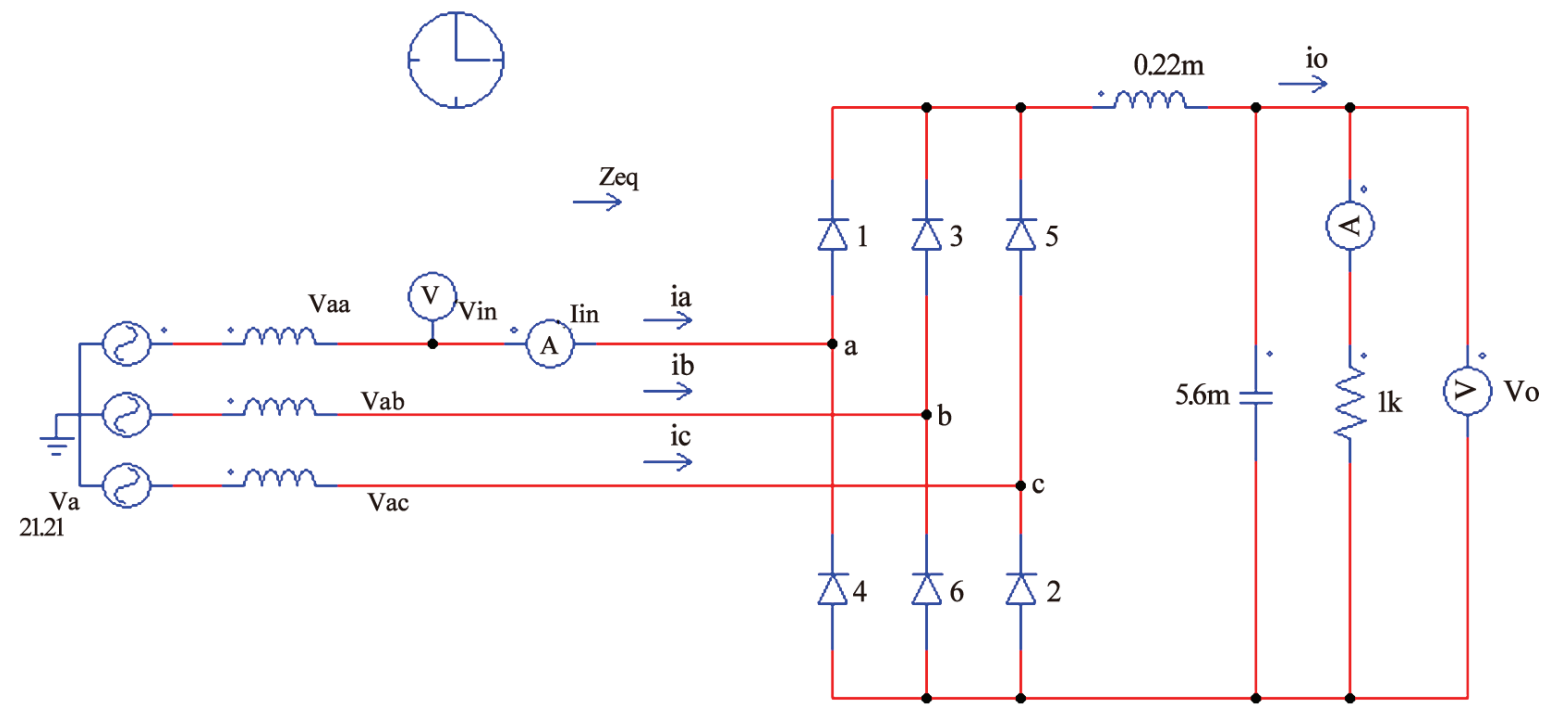

Figure 13. Three-phase rectifier with THD reduction

\subsection{Implementation}

Implementation is done up to the LC filter stage. The schematic that is being implemented is shown in Figure 13 with resistance value of $1.2 \mathrm{M} \Omega$. The constructed hardware is given in Figure 14

Table 3 shows the input voltage, output voltage, ripple voltage, and the efficiency.
It is noticed that the efficiency is increasing while the input rms voltage increase. The voltage drop is to overcome the cut-in voltage across the diode. There is some voltage drop observed across the filter inductor due to the change of the current. The voltage drop across the inductor is very small as the current stabilized over a short period of time. 


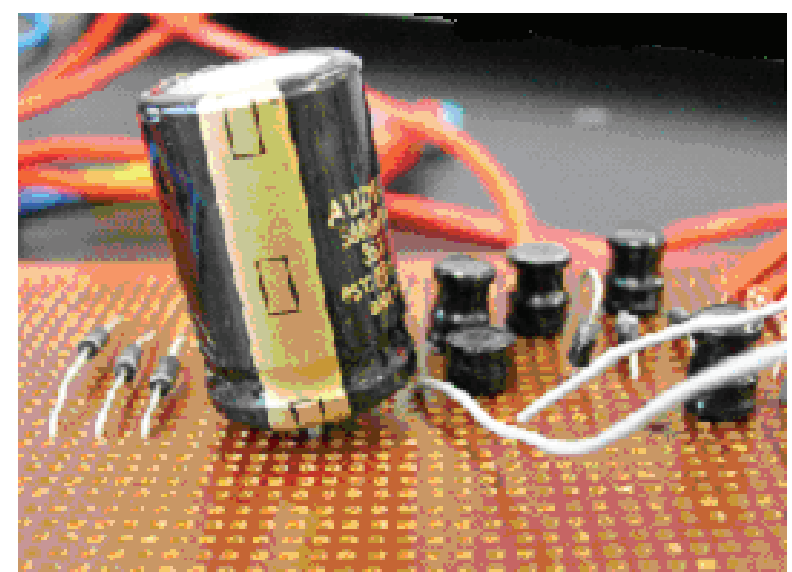

Figurer 14. Hardware implementation of the rectifier

Table 3. Tabulated simulation output

\begin{tabular}{ccccc}
\hline Vin $(\mathrm{rms})$ & $\mathrm{V}_{\text {out }}(\mathrm{V})$ & $\mathrm{V}_{\mathrm{r}}(\mathrm{mV})$ & $\mathrm{V}_{\mathrm{r}}$ & Efficiency \\
\hline 2 & 1.3 & 12.96 & $0.978 \%$ & $46.87 \%$ \\
4 & 4.2 & 41.18 & $0.992 \%$ & $73.38 \%$ \\
6 & 7.0 & 67.81 & $0.972 \%$ & $82.22 \%$ \\
8 & 9.8 & 93.61 & $0.955 \%$ & $86.64 \%$ \\
10 & 12.6 & 123.88 & $0.981 \%$ & $89.29 \%$ \\
12 & 15.5 & 152.06 & $0.984 \%$ & $91.06 \%$ \\
15 & 19.7 & 197.31 & $1.002 \%$ & $92.83 \%$ \\
\hline
\end{tabular}

As the input voltage increases, the efficiency increases because the voltage drop across the diode is a fix value.

The difficulty encountered during the simulation is that the inductor used could not sustain high power such that the inductor will blow off when the input rms voltages exceed $15 \mathrm{~V}$. This can be improved by using bigger inductor. The capacitor filter used could sustain $35 \mathrm{~V}$.

\section{Conclusions}

The design development stages in simulation from studies of fundamental circuits to the development of final design, which utilizes the feedback controller at dc side of the converter to further, improve the current waveform and thus producing an output signal with less distortion and better power factor. This design is then been use as a reference to implement a design in practical manner.

This proves that the feedback controller applied with the step-up converter can help in producing a better output signal.

The goal to achieve low harmonic distortion, high power factor and low ripple voltage can be achieved. The implementation is of low cost and the components used are easy to obtain.

The development of the power factor corrector could be used in some other aspect such as three-phase airconditional circuit, or three-phase induction motor. In order to activate the power factor corrector on the ac-dc converter circuit, more research needed to be done.

The converter's components are designed in such a way that it can sustain the load resistance from $10 \Omega$ to $100 \mathrm{k} \Omega$. The rise time is maintained to be less than 0.5 seconds and the output voltage and current are critically damped. This is to ensure that transient output would not damage the equipment connected to it.

\section{REFERENCES}

[1] N. N. Barsoum and W. K. Janng, "Programming of PIC micro-controller for power factor correction," CD Proceeding of Asia Modeling symposium AMS, Phuket, Thailand, pp. 14-18, 27-30 March 2007.

[2] N. N. Barsoum and F. Png, "High quality ac power with TRIAC inverter," CD Proceeding of Australian Universities in Power and Energy Conference AUPEC, Melbourne, Australia, 10-13 December 2006.

[3] P. Spasov, "Microcontroller technology: The 68HC11," 3rd Ed., Prentice Hall International, 1999.

[4] K. Ogata, "Modern control engineering," 4th Ed., Prentice Hall International, 2002.

[5] N. Mohan, T. M. Undeland, and W. P. Robbins, "Power electronics, converters, applications and design," John Wiley \& Sons, Inc, 2003.

[6] L. Van Der Sluis, "Transients in power systems," John Wiley \& Sons, Ltd, 2002.

[7] J. M. Bourgeois, "Circuit for power factor correction with regards to mains filtering," STMicroelectronics, Italy. Retrieved August 23rd, 2006 from http://www.st.com/ston line/proucts/literature/an/3727.htm.

[8] N. N. Barsoum and M. R. Harris, "Theorems of torque coefficients on stability for induction and reluctance machines," International Journal of Electrical Engineering Education IJEEE, Manchester Institute of Science and Technology UMIST, UK, Vol. 38, No. 3(7), pp. 260-275, 2001.

[9] N. N. Barsoum and S. K. Wong, "Implementation of an active converter for high quality dc power performance," Proceeding of International Conference on Electric Machines ICEM, in CD, Chania, Greece, 2-5 September 2006.

[10] D. A. Neamen, "Semiconductor physics and devices: Basic principles," 3rd Ed., McGraw-Hill International, 2003.

[11] Power Factor, LM Photonics Ltd. Retrieved September 8th, 2006 from http://www.lmphotonics.com/pwrfact.htm.

[12] http://www.uoguelph.ca/ antoon/circ/vps.htm. 